\title{
Livros do Mal: da publicação virtual à autolegitimação editorial
}

\author{
Livros do Mal: From Virtual Publishing to Editorial Self-Legitimation
}

Livros do Mal: de la publicación virtual a la autolegitimación editorial

Rosângela Fachel de Medeiros*

\section{Resumo}

Neste trabalho buscamos analisar a configuração e a atuação da editora independente Livros do Mal (de 2001 a 2004), no âmbito do Sistema Literário Brasileiro (Even-Zohar, 2003a) Contemporâneo. Para isso, retomamos o contexto de criação da editora influenciado pela experiência emergente da publicação online compartilhada por seus editores/escritores e pelo sucesso do e-zine CardosOnline. E realizamos uma breve revisão dos nove títulos publicados pela editora, enfatizando repertórios recorrentes e tentando esboçar um perfil editorial. Em seguida, atentamos para o encerramento do projeto editorial, decorrente do impasse entre as funções de escritor e de editor, sintetizando alguns dos legados da editora.

Palavras-chave: Livros do Mal, literatura brasileira contemporânea, internet, editoração, sistema literário brasileiro.

Abstract

In this work we analyze the configuration and performance of the independent publishing house Livros do Mal (from 2001 to 2004), within the scope of the Contemporary Brazilian Literary System (Even-Zohar, 2003a). To do this, we focus on the context of the publisher's creation, influenced by the emerging experience of online publishing shared by its editors/writers and by the success of the CardosOnline e-zine. We conduct a brief review of the nine titles published by the publisher, emphasizing the recurring repertoires and trying to draw an editorial profile. Finally, we focus on the end of the editorial project, which resulted from the impasse between the functions of writer and editor, summarizing part of the legacy of the publishing house.

Keywords: Livros do Mal, contemporary Brazilian literature, internet, editorial, Brazilian literary system.

\section{Resumen}

En este trabajo analizamos la configuración y desempeño de la editorial independiente Livros do Mal (de 2001 a 2004), en el ámbito del Sistema Literario Brasileño Contemporáneo (Even-Zohar, 2003a). Para ello, nos enfocamos en el contexto de creación de la editorial, influenciado por la experiencia emergente de la publicación online compartida por sus editores / escritores y por el éxito de la e-zine CardosOnline. Al mismo tiempo realizamos una breve revisión de los nueve títulos publicados por la editorial, haciendo hincapié en los repertorios recurrentes y tratando de trazar un perfil editorial. Por último, nos concentramos en el cierre del proyecto editorial, surgido del impasse entre las funciones de escritor y editor, resumiendo parte del legado de la editorial.

Palabras-clave: Livros do Mal, literatura brasileña contemporánea, internet, editorial, sistema literario brasileño.
A literatura é o essencial ou não é nada. O Mal - uma forma penetrante do Mal - de que ela é a expressão tem para nós, creio eu, o valor soberano. Mas esta concepção não impõe a ausência de moral, exige uma 'hipermoral'. A literatura é comunicação. A comunicação impõe a lealdade: a moral rigorosa, neste aspecto, é dada a partir de cumplicidades no conhecimento do Mal, que estabelecem a comunicação intensa. A literatura não é inocente, $e$, culpada, ela enfim deveria se confessar como tal.

Georges Bataille, A literatura e o mal

\footnotetext{
Universidade Federal de Pelotas (UFPel), Pelotas, RS, Brasil. (Dorcid.org/0000-0002-0413-5098. E-mail: rosangelafachel@gmail.com
} 
No início do século XXI, surgia em Porto Alegre, capital do Rio Grande do Sul, a Editora Livros do Mal (LdM), ${ }^{1}$ resultado do desejo que um grupo de jovens amigos tinha de ver seus textos, bem como os de outros jovens escritores, publicados. Foram seus fundadores os escritores Daniel Pellizarri (1974, Manaus) e Daniel Galera (1979, São Paulo), e o artista plástico e ilustrador Guilherme Pilla (1979, Porto Alegre). O trio de amigos que fundou a editora já era conhecido na cena cultural alternativa de Porto Alegre por sua atuação como redatores no $e$-zine $e^{2}$ CardosOnline (COL). Igualmente interessados por questões culturais e literárias, as rotas dos jovens escritores/editores Pellizzari e Galera já havia confluído por ocasião da participação na consagrada Oficina de Criação Literária, ${ }^{3}$ ministrada pelo escritor gaúcho Luiz Antônio de Assis Brasil (1945, Porto Alegre) no Programa de Pós-graduação em Letras da Pontifícia Universidade Católica do Rio Grande do Sul (PUC-RS). A busca por esta formação acadêmica, que tem como objetivo aprimorar o fazer literário por meio de exercícios de escrita e de análise textual, revela o desejo destes então aspirantes a escritores de lapidar suas "ferramentas" literárias e, como efeito colateral, legitimar sua produção textual no âmbito do sistema literário regional.

Além do interesse na produção cultural com ênfase na produção literária, Galera, Pellizzari e Pilla tinham em comum o contexto universitário (quando se conheceram estudavam Comunicação Social em faculdades da área no Rio Grande do Sul - a Fabico/UFRGS e a Famecos/PUC-RS) e a origem em famílias de classe média. Nascidos na década de 1970, eles tiveram a infância marcada pelo processo de redemocratização do Brasil.

A epígrafe que abre este artigo é a mesma que foi utilizada na apresentação da editora em seu site e, em ambos os casos, objetiva desvelar ao leitor a relação que a escolha do nome da editora, Livros do Mal, busca estabelecer com uma tradição literária, como esclarecem os editores/autores:

"Livros do Mal" é tríplice: uma piada interna, uma homenagem a Baudelaire (As flores do mal) e um manifesto de sintonia com o nosso teórico-padrinho, o francês Georges Bataille. Ele fala sobre o Mal intrínseco à literatura, que toda verdadeira arte deve assumir. É o "mal" que traz mudança - ou seja, um "bem" que não é simplesmente "bom" (ou inofensivo) (Galera, Pellizzari e Pilla, 2002, s.p.).

A escolha do nome revela, então, não apenas o posicionamento da editora em relação ao fazer literário e à função da literatura, mas, principalmente, à tradição literária a que estes jovens empreendedores do negócio literário - escrita e editoração - desejavam se filiar. Mas, se o nome da editora deriva da erudição da formação literária de seus criadores, remetendo a um ícone da literatura maldita francesa, a escolha da imagem de um pinto saindo da casca do ovo para a logomarca da editora (Figura 1), desenhada por Pilla, revela a irreverência e a ironia com as quais a editora queria se inserir no sistema literário brasileiro contemporâneo.

A imagem que alude ao nascimento e à juventude da editora também brinca com o sentido popular e coloquial da palavra "pinto", usada para designar o órgão sexual masculino, instaurando assim um humor quase pueril, por exemplo, nas entrevistas concedidas pelo "pinto", alcunha coletiva por meio da qual os criadores da editora se pronunciavam.

Fundada em 2001 com financiamento do Fumproarte, a LdM esteve em atuação até 2004, publicou nove livros e, em 2003, recebeu o Prêmio Açorianos de Literatura na categoria Editora. Com o slogan: "Leiam o novo. É trimmmassa", a editora buscou integrar ao sistema literário brasileiro autores que, até então, estavam em sua maioria inéditos no âmbito editorial hegemônico comercial. Sua proposta inovadora apostava na autogestão e autolegitimação das publicações ao utilizar como alicerce o background da internet. A editora marcava o surgimento de uma nova geração literária nascida com o século XXI, que advinha do território então ainda

\footnotetext{
${ }^{1}$ Seguiremos nomeando a editora pela sigla - LdM.

${ }^{2}$ E-zine é uma versão virtual do fanzine (fan magazine), publicação realizada por aficionados de algum tipo de produção cultural que o utilizam para dar vazão a suas opiniões, mas também para criar conteúdo referente a essas produções.

${ }^{3}$ Em atividade desde 1985, já passaram pela oficina muitos escritores que viriam a alcançar sucesso e reconhecimento nacional e internacional, como Michel Laub, Amilcar Bettega, Cíntia Moscovich, Leticia Wierzchowski, Daniel Galera, Paulo Scott, Daniel Pellizzari, Carol Bensimon e Luisa Geisle.
} 
nebuloso da internet e, de certa forma, foi reconhecida como uma renovação no perfil da literatura contemporânea nacional.

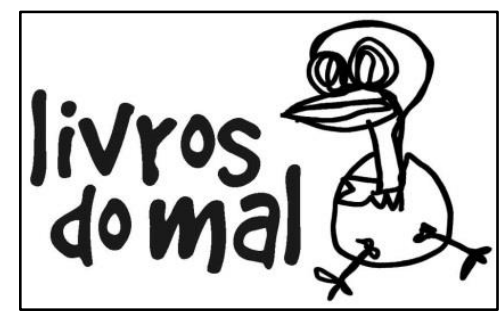

Figura 1 - Logomarca da Editora LdM, criado por Guilherme Pilla

Fonte: site da editora. ${ }^{4}$

Buscaremos analisar a atuação da LdM, seus processos de produção e de publicação, no contexto do sistema literário brasileiro contemporâneo pela perspectiva proposta por Itamar Even-Zohar, que abrange o dinamismo da inter-relação entre:

\begin{tabular}{|c|c|}
\hline \multicolumn{2}{|c|}{ INSTITUIÇÃO [contexto] } \\
\hline $\begin{array}{l}\text { PRODUTOR [emissor] } \\
\text { (escritor) }\end{array}$ & $\begin{array}{c}\text { [receptor] CONSUMIDOR } \\
\text { (leitor);sEp: }\end{array}$ \\
\hline & \\
\hline
\end{tabular}

Ou seja, que concebe o "sistema literário" como:

A rede de relações hipotetizada entre uma certa quantidade de atividades chamadas "literárias", e consequentemente, essas atividades observadas através dessa rede. Ou: $\mathrm{O}$ conjunto de atividades - ou qualquer parte dele - para que relações sistêmicas que fundamentam a opção de considerá-las "literárias" podem ser hipotetizadas (EvenZohar, 2003a, p. 23).

Para isso, propomos uma revisão da trajetória da editora, desde sua criação como desdobramento do CardosOnline, até seu encerramento.

\section{COL - CardosOnline: fanzine por e-mail}

O CardosOnline (COL) 5 foi criado por André Czarnobai em 1998 como um fanzine digital, que era enviado por ele aos amigos por e-mail, e acabou por transformar-se em uma publicação semanal com oito redatores: André Czarnobai (o próprio Cardoso, do qual advém o nome do zine), Daniel Galera, Marcelo Träsel, Guilherme Pilla, Guilherme Caon, Clarah Averbuck, Daniel Pellizzari (Mojo) e Hermano Freitas, numa época em que os blogs começavam a aparecer (Figura 2). Em 2000, o perfil da publicação foi apresentado em sua página de divulgação: ${ }^{6}$

O CardosOnLine (COL) é um fanzine digital produzido em Porto Alegre e distribuído exclusivamente por e-mail. Escrito por um staff de 8 colunistas, com uma edição por semana, o COL trata de cultura alternativa, cinema, música, literatura, mídia e artes em geral, publicando também contos, crônicas, poesia e egotrips (CardosOnLine, 2000, s.p.).

\footnotetext{
${ }^{4}$ Disponível em: http://cabrapreta.org/ldm/imagens/logo_pinto_300dpi.jpg

${ }^{5}$ Apesar de não estar mais em atividade, o site de divulgação do zine é mantido no ar e pode ser acessado por meio do link: http://cabrapreta.org/COL/. Seguiremos nomeando a publicação pela sigla COL.

${ }^{6}$ Disponível em: http://cabrapreta.org/COL/index.html
} 


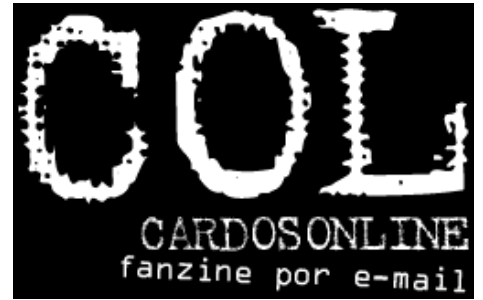

Figura 2 - Logomarca do COL - Cardosonline

Fonte: site do COL.7

A ideia de formalizar a publicação veio de Daniel Galera, um dos destinatários dos e-mails Czarnobai, e que viria a se tornar um dos colunistas da publicação:

Quando li as mensagens que o Cardoso tava mandando pros amigos durante a greve da UFRGS, em 1998, tive o insight - uma publicação por e-mail, com colunistas fixos, coisa e tal. Falando de cultura, drogas, textos subjetivos. Hoje parece uma coisa tão comum, banal, mas há três anos era algo praticamente inédito no Brasil. Juntamos um pessoal e começamos a escrever (Galera, 2002). ${ }^{8}$

É interessante destacar que esses jovens escritores reconheceram o potencial latente da internet como uma nova e acessível plataforma para a publicação. "Usávamos a internet como meio de publicação, achávamos que ela dominaria a cena literária, criando novas formas de se expressar" (Deves, 2016), disse Galera em uma entrevista, anos após suas aventuras literárias virtuais. Essa potência literária do ambiente virtual era visionariamente reconhecida por eles, como explicava na época Pellizzari, a respeito da criação de sua obra folhetinesca Quatro garantas cortadas (1996-1997):

Escritores são uma raça engraçada.

Quatro gargantas cortadas foi criada por um deles, para dar vazão às suas idéias mais atípicas, esquizóides e experimentais.

Alguns quilos de ficção científica, uma pitada de sátira, duas colheres de pretensão, um pé de balbúrdia pop e falta de autocrítica a gosto: estes são os ingredientes principais desta minha nova empreitada no divertido mundo dos bytes (que, ainda mais do que o papel, aceitam qualquer coisa - e são mais baratos) (Pelizzari, 1997).

Ao apresentar o objetivo de seu cyberfolhetim pop de ficção científica, Pellizzari destaca a facilidade de publicar na internet, brincando com o fato de que os bytes aceitam tudo, mas, na verdade, o que está em questão é que, para a publicação na internet - à época e ainda hoje -, não há a necessidade de responder e/ou de estar inserido na estrutura do sistema literário impresso. E, além disso, essa publicação independente, diferentemente de quando feita de forma impressa, não requer(ia) grande investimento financeiro - para tanto, bastava possuir um computador, conexão à internet e ter conhecimentos básicos de programação. No entanto, apesar de Pellizzari fazer referência à facilidade e à liberdade para publicar na internet, naquela época, publicar na internet demandava conhecimento específico, mesmo que básico, de programação e domínio das então rudimentares ferramentas de publicação (linguagem HTML) ${ }^{9}$ e de busca na internet, uma vez que ainda não existiam plataformas ou ferramentas específicas para isso - a moda dos blogs despontaria apenas em 1999. ${ }^{10}$ Em seu folhetim, Pellizzari usou e

\footnotetext{
${ }^{7}$ Disponível em: http://cabrapreta.org/COL/

${ }^{8}$ Trecho de entrevista concedida por Daniel Galera ao site Prólogo, em 2001, atualmente disponível no Portal Cabra Preta, de Daniel Pellizzari: http://cabrapreta.org/ldm/clip_prologo.html

${ }^{9}$ Abreviação do termo inglês: HyperText Markup Language, utilizada para a criação de páginas Web.

${ }^{10} \mathrm{O}$ advento dos blogs, ambiente virtual construído para facilitar a publicação de textos, bem como a transformação do ambiente virtual com ferramentas que simplificaram e facilitaram a autoria no contexto da internet, eliminando a necessidade de conhecimentos técnicos de programação, democratizou ainda mais a rede como espaço de manifestação de conteúdo autoral.
} 
abusou, dentro das possibilidades técnicas da época, do hipertexto e da hipermídia, explorando a possibilidade de romper o limite bidimensional do papel. E, conjuntamente com Galera, foi também responsável pela criação da homepage do CardosOline, uma vez que ambos já possuíam alguma experiência no universo da publicação virtual.

Pellizzari já havia colocado no ar, em 1996, sua obra-virtual-colaborativa Quatro gargantas cortadas: um folhetim pop de ficção esquizodélica. ${ }^{11}$ Além do conteúdo literário e da interação com seus leitores/coautores, o autor era responsável por todo o desenvolvimento e manutenção da página, como fica evidente nos créditos da publicação (Figura 3).

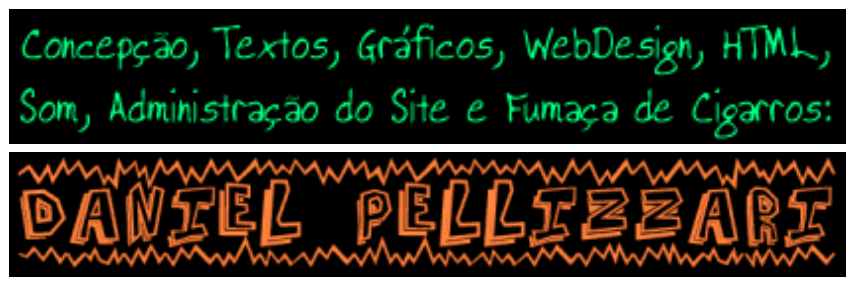

Figura 3 - Créditos do blog-folhetinesco Quatro gargantas cortadas

Fonte: Folhetim Quatro gargantas cortadas. ${ }^{12}$

No mais profundo entendimento da possibilidade de "produção colaborativa" - que seria instaurada pela linguagem wiki - oferecida pelo então incipiente território da internet, Pellizzari instigava seus leitores a participarem na realização dos capítulos de seu folhetim, pedindo a colaboração/ajuda de seus leitores como coautores, no link Ajuda:

A proposta é a seguinte:

Este é um folhetim nada cartesiano, que será escrito em alguns meses com a ajuda dos leitores / coautores.

Aproximadamente a cada dez dias, quatro novos episódios entrarão no ar.

Os leitores são encorajados a dar sugestões, participando assim da gestação das tramas. Participar é fácil: leia os episódios, depois dê suas sugestões. Espere dez dias e veja o que aconteceu. Não é singelo?

Espero que funcione.

Bueno, é isso.

(Oh, como se já não fosse complicado o bastante conseguir editor e público para meus trabalhos principais...) (Pelizzari, 1997).

Para promover, instigar e facilitar a participação/interferência dos leitores na narrativa o escritor/webdesigner disponibilizava um espaço específico, intitulado Participe:

Agora que você já tem uma vaga noção de onde seus ricos pezinhos estão pisando, é hora de brincar de Deus e influir nos destinos das Quatro Gargantas Cortadas.

Jesus Cristo é mesmo um vampiro? Qual a relação entre anões e noz-moscada? O que o velho sabe sobre os marcianos? Roberto Carlos tem culpa? Qual a cor de um rato

fluorescente? Norival vai destruir o planeta? Quem tem o molde do viril membro de Jimi

Hendrix? João Bosco é mesmo o máximo? O que quindins têm a ver com tudo isso?

Estas são algumas das perguntas que você pode ajudar a responder. Sinta-se livre para criar novas situações, introduzir novos personagens - enfim, qualquer coisa. Deixe sua mente repousar na mansidão do Caos e espere pelo resultado (Pelizzari, 1997).

A colaboração acontecia, então, via mensagem, enviada por meio da própria página Web, na qual o leitor/colaborador precisava informar seu nome e e-mail e, em seguida, escrever no

\footnotetext{
${ }^{11} \mathrm{O}$ site da produção ainda pode ser visitado em: http://cabrapreta.org/4gc/

${ }^{12}$ Disponível em: http://cabrapreta.org/4gc/creditos.html
} 
espaço: "Suas sugestões para o próximo episódio". Caso esse espaço não fosse suficiente para a colaboração, o leitor tinha ainda a possibilidade de enviar sua colaboração por e-mail.

Por sua vez, Galera criou o Proa da palavra, em 1997, uma das primeiras páginas a publicar conteúdo literário na internet, a qual manteve em atuação até 2001.

A Proa da palavra foi um projeto pessoal que inventei em 1997. Imaginei como seria legal ter um site de literatura publicando textos de escritores iniciantes. Me dei conta que era relativamente fácil de fazer, então fui lá $\square$ e fiz. Criei o site, divulguei com cartazes, editei semanalmente a revista. Deu mais certo do que eu pensava, durou quatro anos. Recebia cerca de 100 colaborações por semana, era incrível. Mas depois de muito tempo, fui cansando. Comecei a perder a motivação, porque os textos que chegavam eram ruins, e comecei a me dedicar a outros projetos. A Proa fechou seu ciclo, nasceu cresceu e morreu, influenciou vários outros sites de literatura na rede, que imitaram o formato. Aprendi muito sobre programação, edição e literatura por causa dessa experiência. Valeu, mas terminou (Colonetti, 2010, p. 51).

Já o artista gráfico Guilherme Pilla vinha do mundo dos zines analógicos e do universo cinematográfico independente de Porto Alegre. Ainda é possível visitar e explorar a exposição virtual Mondo Guigui, referente à produção do artista durante o tempo de existência e atuação da LdM.13

Ao levarem a literatura para esse novo e desconhecido território que a internet representava, Pellizzari e Galera e, na sequência, a trupe do CardosOnline, inseriram novos elementos e paradigmas na estrutura do sistema literário, que, conforme Even-Zohar, compreende como internas todas as atividades que possam ser etiquetadas como "literárias".

A percepção visionária do incrível potencial comunicacional que a internet apresentava, que foi explorado pela atuação do COL, levou seus editores a se autointitularem os criadores da internet, como afirmou André Czarnobai - o Cardoso, em uma entrevista.

[Inventamos a internet] aos 20 e poucos, sem querer, de madrugada, em roupas de baixo, sob o efeito de substâncias divertidas, em porões, sótãos e quartos escuros quase sempre localizados na casa de nossos pais (Arrais, 2008) .

Para Pellizzari, o COL anteviu muitos dos elementos que viriam a ser desenvolvidos pela Web 2.0, principalmente, em relação ao que viria ser denominado de prossumidor $=$ produtor + consumidor. "Fomos precursores do senso de comunidade e de interação entre produtores e consumidores de conteúdo, que a partir de determinado momento se tornaram uma coisa só". (Arrais, 2008). A própria apresentação do e-zine - em sua homepage de divulgação - propunha uma reflexão a respeito das novas possibilidades que a internet propiciava ao campo da literatura e da leitura, e que a publicação procurava explorar e desenvolver:

O sucesso do COL mostra que a internet não é um palco exclusivo da subliteratura. Pelo contrário, é um vasto e democrático laboratório onde escritores podem levar sua produção ao público, debater, experimentar e enfrentar o julgamento de leitores. O contato entre autor e leitor, na internet, é direto. O COL prova que ainda existem leitores genuínos numa época em que os jornais aumentam o tamanho de suas letras, estreitam seus formatos e enchem as páginas com imagens enormes em 4 cores; época em que os romances dificilmente ultrapassam 200 páginas; época em que supostamente ninguém mais lê, onde a informação deve ser telegráfica, em que a elaboração visual importa mais do que aquilo que está escrito. Mas o COL, com seus $70 \mathrm{~kb}$ de texto puro em duas edições semanais, demonstra que tem muita gente por aí lendo e, sobretudo, escrevendo (Cardosonline, 2001). ${ }^{14}$

Com a periodicidade de duas edições semanais, o COL circulou até 2001, totalizando 278 edições e chegando a cinco mil assinantes, número que, no entanto, não corresponde ao efetivo de leitores do zine, uma vez que o material da publicação era disseminado pelos assinantes via e-mails. A publicação virtual norteada pela tecnologia do e-mail permitia um contato direto

\footnotetext{
${ }^{13}$ Disponível, atualmente, no site Cabra Preta: http://cabrapreta.org/ldm/mondoguigui.htm

${ }^{14}$ Disponível em: http://cabrapreta.org/COL/col_sobre.html
} 
entre leitores e autores, pois, como logo foi reconhecido pelos redatores do COL, o advento da internet criara um espaço novo, livre e gratuito, que encurtou o caminho entre o texto e seus possíveis leitores. Ao reconhecerem a emergência de um novo contexto (internet), que possibilitava novos canais (o e-mail e a publicação on-line), nos quais, além dos antigos repertórios literários, somavam-se novos códigos (hipertexto, hipermídia), estes jovens produtores visualizaram e promoveram uma transformação no sistema literário, encontrando novas formas de chegar aos receptores e desenvolvendo uma estrutura marginal que logo foi ganhando espaço no contexto do sistema vigente. Talvez, mais do que em relação a uma possível inovação do texto literário (forma e conteúdo), a grande força dessas primeiras experiências de literatura na e pela internet esteja na forma como, atuando na conexão de interesses norteada pelo domínio de repertórios ${ }^{15}$ compartilhados, conseguiu aproximar produtores e consumidores, burlando a necessidade de mediação e de reconhecimento de instituições acadêmicas e mercadológicas, e estabelecendo uma estrutura marginal e periférica que, no entanto, não tardou em chamar atenção.

Mais que uma publicação para disseminação de conteúdo literário, o COL logo se consolidou como uma referência no âmbito cultural regional e se consagrou com a criação do Bailão do COL, festa que era organizada pelos colunistas do e-zine no Garagem Hermética. ${ }^{16}$ No entanto, com o passar do tempo, a fórmula se desgastou e os colunistas foram se envolvendo com outros projetos. A proclamação oficial de extinção do e-zine ainda pode ser lida na internet:

Seguinte, rapeize: O Cardosonline acabou. A edição 278 foi a última formal do zine. [...] Ainda estamos recebendo uma penca de assinaturas diariamente, mas é sério: podem parar. O COL foi extinto em consenso pelo staff de colunistas. Motivos? Nenhum específico, mas, de forma geral, cada um de nós se envolveu em projetos e rumos diferentes nos últimos meses, e também sentimos que a fórmula do COL estava esgotando sua vida útil e o zine fechou seu ciclo (Cardosonline, 2001). ${ }^{17}$

Foi da atuação e do encontro no COL que Pellizzari, Galera e Pilla, que já se arriscavam e experimentavam na produção de conteúdo literário na internet, derivaram para a criação da LdM. Assim, na mesma página em que se anuncia o encerramento das atividades do COL são apresentados os novos projetos de seus integrantes. Pellizzari, Galera e Pilla anunciavam, ao mesmo tempo, a criação da LdM e o lançamento de seus primeiros livros. Enviada em setembro de 2001, a última edição do COL chegou a quase cinco mil assinantes no Brasil e no exterior.

A rapidez de produção textual exigida pela periodicidade semanal do e-zine associada ao feedback direto dos leitores criaram um laboratório ideal para estes jovens autores experimentarem e aperfeiçoarem suas habilidades e aptidões literárias. Além disso, como herança da ampla divulgação permitida gratuitamente pela internet, eles levaram consigo o vasto público formado pelo COL.

\section{Livros do Mal - uma cooperativa do livro}

De acordo com a descrição do projeto da LdM, assinada pelos fundadores da editora, a ideia não era criar uma editora no sentido formal da palavra,

\footnotetext{
${ }^{15}$ Usamos o termo repertório na acepção cunhada por Itamar Even-Zohar, de "conjunto de leis e elementos (sejam os modelos isolados, ligados ou totais) que regem a produção de textos. Enquanto algumas destas leis e destes elementos parecem ser universalmente válidos desde as primeiras literaturas do mundo, é claro que grande quantidade de leis e de elementos estão sujeitos a condições de mudanças em diferente períodos e culturas. Este setor local e temporal do repertório é a fonte das lutas no sistema literário (ou em qualquer outro sistema semiótico). [...] o status de qualquer repertório literário está determinado pelas relações que existem no (poli)ssistema. Obviamente, um repertório canonizado é apoiado por elites conservadoras ou inovadoras e, consequentemente, está limitado pelas pautas culturais que regem o comportamento daquelas. Se a elite reclama sofisticação e excentricidade (ou o contrário, isto é, "simplicidade" e conformismo) para satisfazer seu gosto e controlar o centro do sistema cultural, o repertório canonizado se aderirá a estes traços tão firmemente quanto possível” (Even-Zohar, 2003b, p. 10). Nesse sentido, seriam repertórios compartilhados por produtores e receptores do COL: a utilização da internet e de suas ferramentas emergentes (neste caso específico, o e-mail), a linguagem, bem como referências literárias e culturais.

${ }^{16} \mathrm{O}$ Garagem Hermética foi durante muito tempo um lugar de referência no circuito alternativo de shows e festas de Porto Alegre.

${ }^{17}$ Disponível em: http://www.qualquer.org/col/
} 
[...] e sim um esforço de publicação independente, apoiado na simples vontade de fazer um trabalho legal, fazer livros, divulgar nossa literatura e divulgar a literatura de outros escritores desconhecidos cujo trabalho admiramos. A Livros do Mal é uma cooperativa: talvez seja esse o termo mais adequado. Nela investimos nosso dinheiro, e nosso retorno deve ser o prazer de ver livros de nossa autoria impressos e divulgados, e de poder publicar ainda outros autores. E não queremos apenas editar livros: queremos dar uma socializada no que a produção literária e artística deste país tem de mais legal, debater, compartilhar, discutir rumos, alcançar o máximo número de pessoas que for possível (Galera, Pellizzari e Pilla, 2003, s.p.).

Ainda em seu manifesto a respeito da criação e da atuação da LdM, os produtores afirmavam o desejo de "dar espaço para a produção e discussão do novo na literatura", catalisando literatura "que traga visões novas, que ultrapassem o exercício estético vazio, o lugar-comum da classe média ou deslumbramento com o mundo pop". Com o objetivo de "lançar títulos com propostas menos tradicionais", dando visibilidade a "autores iniciantes e talentosos que andam produzindo literatura por aí, alguns deles participantes dos meios eletrônicos de laboratório e divulgação" (Galera, Pellizzari e Pilla, 2003, s.p.).

O projeto da editora revela, então, a insatisfação dos jovens produtores (artistas/editores) com os paradigmas perpetrados pelas instituições literárias vigentes que, segundo eles, regiam o mercado editorial brasileiro, responsáveis por definir a estrutura do sistema literário nacional, bem como por estabelecer os elementos responsáveis pela canonização "de normas e obras literárias (isso é, tanto modelos como textos)" aceitos como legítimos nos círculos dominantes da cultura "e cujos produtos mais marcantes são preservados pela comunidade para que formem parte de sua herança histórica" (Even-Zohar, 2003b, p. 7).

O que os produtores da LdM apontam de maneira juvenil e um tanto ingênua é o entendimento de que a "boa reputação" literária resultaria da ação direta e objetiva de algum grupo de pessoas e/ou instituições. No entanto, esta perspectiva já era refutada por Pierre Bourdieu, em 1977, e retomada por Even-Zohar, que chamava a atenção para o fato de que tais reputações são resultado do "campo de produção como sistema de relações objetivas entre os seus agentes ou as suas instituições e como lugar de lutas pelo monopólio do poder de consagração onde se engendra continuamente o valor das obras e a crença nesse valor" (Bourdieu apud Even-Zohar, 2003b, p. 36). E será justamente essa tensão sistêmica entre a estabilização e a inovação que dará espaço à LdM e a suas obras e irá colaborar para sua reputação e seu reconhecimento no interior do sistema literário.

Enquanto editora independente, a LdM foi criada como o desejo de ser um contraponto ao modelo editorial vigente. Sua atuação pode ser definida como amadora, no duplo sentido da palavra, na medida em que era realizada por pessoas que amavam o que faziam e que estavam completamente envolvidas no processo de edição, o qual, por sua vez, era amador e estava reduzido ao mínimo necessário. Galera e Pellizzari recebiam os originais, selecionavam o que achavam que se encaixava no perfil e na proposta da editora, realizavam a revisão dos textos e, conjuntamente com Pilla, decidiam questões relacionadas à identidade visual das publicações, como o formato dos livros, suas capas e suas ilustrações. Como conta Galera a respeito da edição dos primeiros dois livros da coleção, o seu e o de Pellizzari:

O Mojo (Pellizzari) revisou o livro dele, eu revisei o meu. Bolamos as capas juntos, no computador da minha casa, com base em ilustrações do Pilla. Eu diagramei os livros, finalizei as capas e toquei todo o esquema de gráfica. Eu compilei um mailing e nós mesmos estamos mandando livros e releases para vários lugares, e indo de livraria em livraria tentando vender os livros em consignação. Ou seja: eu, Mojo e Pilla fizemos tudo, mesmo. [...] E pra distribuição, como eu disse, contamos uma rede de representantes em várias cidades, que tentarão vender os livros pra nós. Tudo na base da parceria trimmmassa (Galera, 2002).

Assumindo os papeis de artistas/editores, Pellizzari, Galera e Pilla reconfiguravam a dinâmica do sistema literário exercendo várias posições - e algumas ao mesmo tempo. Nesse sentido, enquanto editores que se autopublicavam, eles possuíam um total controle artístico 
sobre o produto final. E, ao serem os curadores e editores, mantinham uma unidade quase orgânica entre as obras, alicerçada em valores e afinidades estéticas e culturais. No entanto, essa atuação independente buscava o reconhecimento e a integração dessa produção no sistema vigente, com o desejo, talvez audacioso, de provocar uma interferência no modelo, que estaria para além do contexto do texto.

A editora estreou em 2001 publicando duas antologias de contos de autoria de seus editores, dando assim início à Coleção Contra a Capa com: Dentes guardados, de Daniel Galera, e Ovelhas que voam se perdem no céu, de Daniel Pellizzari. Estas primeiras obras foram bem recebidas pelo público e, principalmente, pela crítica regional e nacional. A primeira tiragem com 600 exemplares de cada título foi vendida em dois meses, basicamente no Rio Grande do Sul, graças à rede de divulgação e de contatos fomentada por meio da internet. Mas a repercussão dessas publicações foi nacional, por meio de resenhas e notícias em importantes jornais e revistas do Brasil.

Isso fez com que, já no início de 2002, fosse produzida uma segunda tiragem dessas obras, que foram, então, lançadas em São Paulo, de onde se articulou a distribuição para o resto do país. Nesse mesmo ano, a LdM lançou mais três títulos da Coleção Contra a Capa: Vidas cegas (2002), de Marcelo Benvenutti; Ou clavículas (2002), de Cristiano Baldi; e Humus (2002), de Paulo Bullar. Ainda nesse mesmo ano a editora deu início à Coleção Tumba do Cânone. A primeira obra publicada por essa segunda coleção foi O livro das cousas que acontecem (2002), de Daniel Pellizzari. Já em 2003, seriam publicados mais três livros, os romances: Até o dia em que o cão morreu, de Daniel Galera; Hotel Hell, de Joca Reiners Terron; e o livro de contos Ainda orangotangos, de Paulo Scott, lançado em 2003, que encerrou a trajetória da editora.

\section{Coleção Contra a Capa}

O nome da coleção permite refletir a respeito de algo muito importante na configuração da LdM, o cuidado com a perspectiva gráfica das obras, principalmente, com a elaboração das capas como elemento constitutivo dos livros e da identidade visual da editora. A perspectiva gráfica da editora é uma das que poderiam embasar a reflexão de Marco Lúcio de Souza Góis (2015), para quem

toda "capa" é o resultado de um processo (do gerenciamento de signos, ideológicos que são), cujas marcas das divergências e convergências de sua produção não podem ser verificadas em sua totalidade. O que encontramos ao ler capas, portanto, são pistas, meras lembranças das batalhas pela significação. [...]. Aliás, a capa há tempos deixou de ser mero invólucro para conteúdo dos livros, passando a peça importante em sua produção, comercialização, recepção e, particularmente, na produção de sentidos (Góis, 2015, p. 433).

A arte perturbadora e impactante das capas da Coleção Contra a Capa (Figura 4) ficou por conta de Guilherme Pilla.

A unidade artística das capas não apenas instaurou uma identidade visual à coleção, mas, principalmente, estabeleceu um diálogo intertextual das obras da coleção com um contexto de cultural visual da linguagem das HQs e da arte contemporânea, com o qual os editores/autores e, por conseguinte, suas obras estavam extremamente ligadas. Sua produção é, de certa forma, a resposta à pergunta lançada pelo jornalista Marcelo Trasel em sua matéria sobre o surgimento da editora: "O que anda escrevendo a geração que se criou escutando Nirvana, assistindo a filmes de Tarantino e lendo textos direto na internet?" (Trasel, 2001).

É importante ter em mente, ainda, como nos lembra Góis (2015), que as capas de livros vêm recebendo, cada vez mais, tratamento especial, uma vez que se constituem como um elemento de apelo comercial, que responde a interesses de propaganda e marketing. Vale lembrar que Galera e Pilla foram estudantes de Publicidade e Propaganda. As capas dos livros da Coleção Contra a Capa representam, então, o completo imbricamento artístico e mercadológico do projeto LdM, que estava presente também na divulgação das obras (para venda) no site da editora. Na página destinada a cada publicação, era possível ver a capa do livro e ler a biografia do autor, algumas críticas (o que foi dito) sobre a obra e um trecho selecionado do texto. 

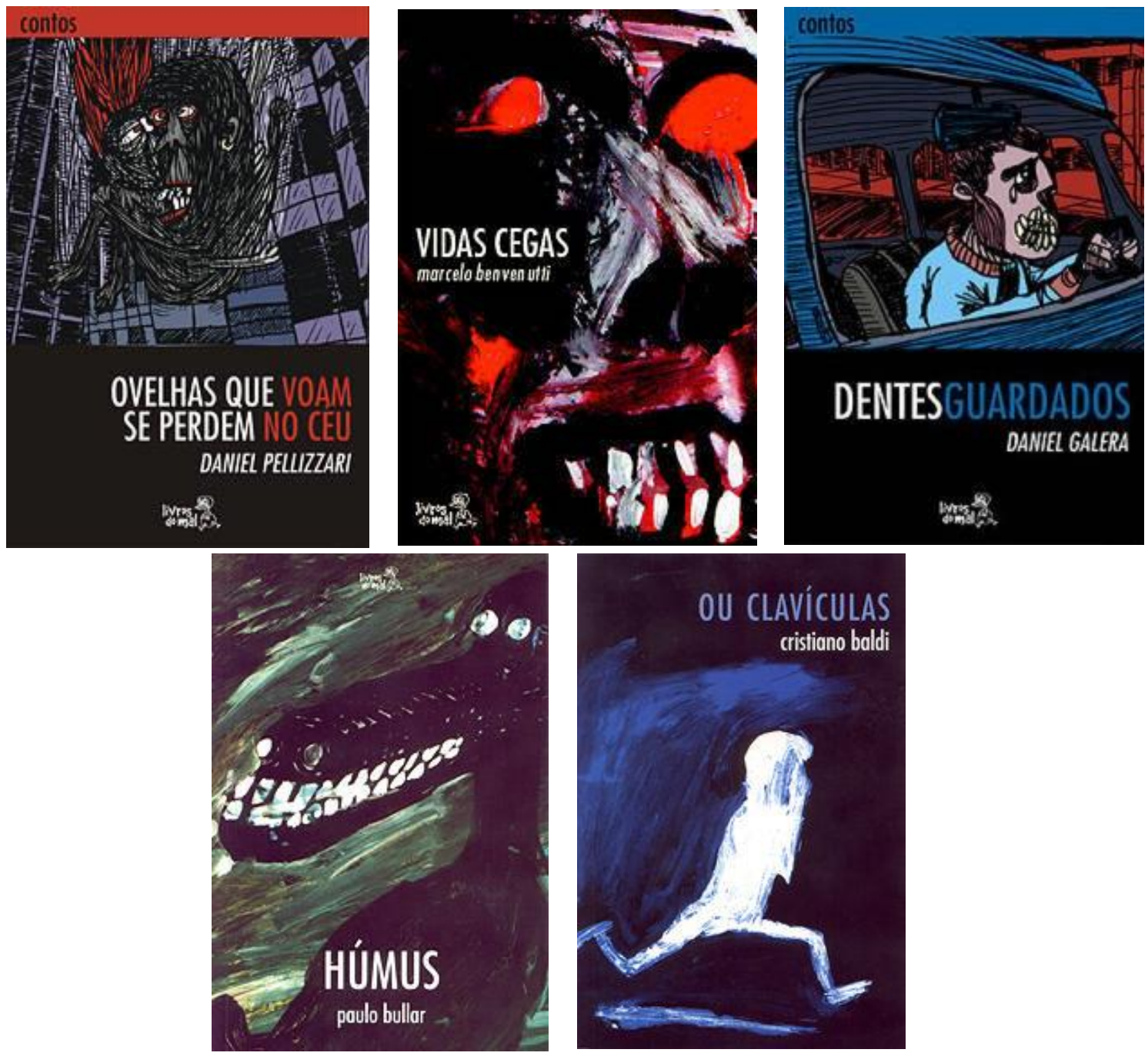

Figura 4 - Capas dos livros da Coleção Contra a Capa.

Fonte: Catálogo da Livros do Mal.18

Ovelhas que voam se perdem no céu, primeira antologia de contos de Pellizzari, transita entre os gêneros fantástico e absurdo, combinando elementos grotescos e mórbidos, apresentando toda a versatilidade estilística que o autor já possuía e experimentava em suas publicações na internet. No trecho selecionado para divulgação do título na página da editora lê-se:

Às vezes confundo Rimbaud com Baudelaire, mas não me importo muito porque a maioria das pessoas que conheço nunca ouviu falar de nenhum deles. Estas duas garotas que estão comigo, por exemplo, não devem saber nem onde fica a França. [...]. Sento na cama, as molas fazem barulho assim nhéc-nhéc e eu fico fazendo nhéc-nhéc até que de repente a índia começa a sangrar bem em cima do lençol que até agora não estava muito sujo. Estava tão branco, agora tem uma mancha vermelho escura, estou menstruada, ela diz, tô vendo. [...]. Me atira a caixinha de $\mathrm{OB}$, não consigo alcançar, sabe, eu não acredito muito nas leis da Física, pego a caixinha do chão, tamanho médio, eu brinco ihh vai precisar de supergrande e a índia me dá um tapa nas costas, não dói, mas ela pede desculpas. Rindo eu peço para colocar o OB nela, a loira falsa tranca os dentes como se estivesse sentindo alguma dor e balança a cabeça, a índia me olha e olha pro sangue e me olha e diz não, você não sabe fazer isso. Sei sim, eu digo, e ela arranca o OB da minha mão e diz vira pra lá. Fico olhando: sempre fui muito curioso (Pellizzari, 2001).

\footnotetext{
${ }^{18}$ Disponível em: http://www.cabrapreta.org/ldm/
} 
Dentes guardados, primeira antologia de contos de Galera, destaca-se na forma como reproduz a fala coloquial, que o autor coloca na boca de seus personagens, característica que se tornaria marca de sua prosa. Os contos giram em torno de situações cotidianas em narrativas que poderíamos chamar de realista, mas nas quais o autor busca revelar a estranheza que habita o cotidiano, como se lê no trecho selecionado para divulgação da obra na página da editora:

Eu tava no bar do Zé comendo uma coxinha de galinha e tomando uma cerveja, nada que eu já não tivesse feito antes. Havia, como de praxe, meia dúzia de pescadores bêbados atirados pelas mesas, uns rindo da cara de outros, outros jogando dominó, um último cambaleando entre as duas mesas de sinuca, coçando o rosto inchado. E meio que do meu lado, a pouco mais de um metro, um outro pescador, maior que todos os outros, mais feio que todos os outros, sacudindo graciosamente um carrinho de bebê dentro do qual havia um bebê. $\mathrm{O}$ carrinho era novo, o bebê era branquinho, limpo, sorridente e silencioso. Eu já tinha visto muita coisa estranha no bar do Zé pra me espantar com um carrinho de bebê com um bebê dentro, no meio daquele boteco escuro, velho, ocupado exclusivamente por homens rudes, grotescos, a maioria miseráveis, todos bêbados. Continuei mastigando minha coxinha. Mas a presença do bebê começou, finalmente, a me causar uma certa estranheza, e eu tirei os olhos do balcão para encarar aquele pequeno ser nos olhos (Galera, 2001).

Esses dois primeiros livros, que apresentaram a editora e seus autores ao sistema literário brasileiro, tiveram boa repercussão de crítica, sendo resenhados pelo colunista da Folha de $S$. Paulo, Bernardo Carvalho, no prestigioso suplemento cultural Ilustrada:

Ovelhas que voam se perdem no céu, de Daniel Pellizzari, e Dentes guardados, de Daniel Galera, são alternativos como iniciativa editorial e muitas vezes podem parecer exercícios de juventude do ponto de vista da literatura. Mas ambos estão investidos de uma noção literária básica para quem escreve contos hoje, depois de Tchecov, Joyce e Kafka. De uma maneira mais ou menos bem-sucedida, os dois não procuram explicar o sentido das coisas e não fecham seus contos com uma moral. Para além do que se passa fora dos livros (na militância editorial), porém, um tem pouco a ver com o outro (Carvalho, 2002).

Sinalizando a juventude da escrita que tinha como contraponto a consciência do fazer literário e o domínio do gênero, o colunista indica ambas as antologias com três estrelas, nada mal para jovens (Pelizzarri então com 27 anos e Galera com 22) e estreantes escritores.

O terceiro livro da coleção a ser publicado foi Vidas cegas, antologia de contos curtos de Marcelo Benvenutti. A obra apresenta uma prosa rápida, objetiva e em terceira pessoa, que em cada narrativa tenta dar conta da vida de algum de seus personagens, tangenciando, em algumas vezes, o limiar do absurdo, como se observa no trecho selecionado para divulgação do título na página da editora:

E Francisco perdia-se em seus próprios pensamentos de felicidade egoísta e humana. Pediu uma cerveja. Ana dirige despreocupada pela cidade. De óculos escuros e fumando um Marlboro Light, Ana brinca de ziguezague pelas ruas vazias de um bairro da periferia. No rádio, uma velha música de um inglês morto. Na mente, álcool da noite anterior. No sangue, cocaína da noite anterior. No estômago, esperma da noite anterior. Na rua vazia um homem que atravessa a frente do carro surgindo do nada de dentro de um bar. No sul da Índia, milhares de pessoas trabalham em uma fábrica de remédios (Benvenutti, 2002).

Humus, quarto livro da coleção, era uma antologia de contos de Paulo Bullar, que resgatava a memória das fábulas para dar voz aos animais que falam com ironia e de forma crítica a respeito da condição humana, que, no caso desses contos, é podre. No trecho selecionado para divulgação do título na página da editora tem-se um exemplo disso:

Quando acordei estava escuro, a leoa ao meu lado. Tonto, mal enxergava; esperei, deitado, que minha pupila focalizasse melhor os arredores de meu novo habitat. Devido à falta de luz, não pude enxergar muita coisa, mas, aos poucos, pude perceber um vulto em frente à jaula, um vulto humano; uma mulher, pra ser mais preciso. [...]. Acordei com fome, alguns quilos de carne me esperavam. Primeiro, comi a carne, depois, a leoa. Passei o dia deitado, na modorra, descansando da foda de merda com aquela leoa decadente. Fiquei observando aquela criatura encolhida, mordendo as feridas das patas. Louca. No fim da 
tarde, a veterinária veio com um funcionário me trazer mais carne. Me olhou nos olhos, sorriu; um sorriso malicioso, de cumplicidade (Bullar, 2002).

Ou clavículas, antologia de contos de Cristiano Baldi e ultimo título da coleção, desvela o estranhamento presente no cotidiano da vida da classe média metropolitana, expondo a violência da solidão, da depressão, e das relações sociais e afetivas, sobretudo, no ato sexual. No trecho selecionado para divulgação do título na página da editora tem-se:

Além de ninfomaníaca e vegetariana, ela era meio professora de História. As escolas (ao menos as particulares) deveriam ter mais professoras como ela. Vez por outra, me trazia da rua uma aluninha para foder. Não sei bem como ela tratava disso. E não era uma dessas bobagens fetichistas, pois ela nem sequer assistia. Deixava a aluna no sofá, nos apresentava e saía para comprar croissant. Comia, no balcão da confeitaria, dois ou três doces, sincronizando com minhas gozadas em casa. Ou então aproveitava uma trepada com alguma figurinha patética que arranjava (Baldi, 2002).

\section{Coleção Tumba do Cânone}

Para essa coleção, cada autor convidou um ilustrador para ser responsável pela arte de seu título. A qualidade e o resultado estético dessas publicações (Figura 5), que buscavam se distinguir do padrão editorial vigente, foi reconhecida pela crítica como um ponto forte da editora.
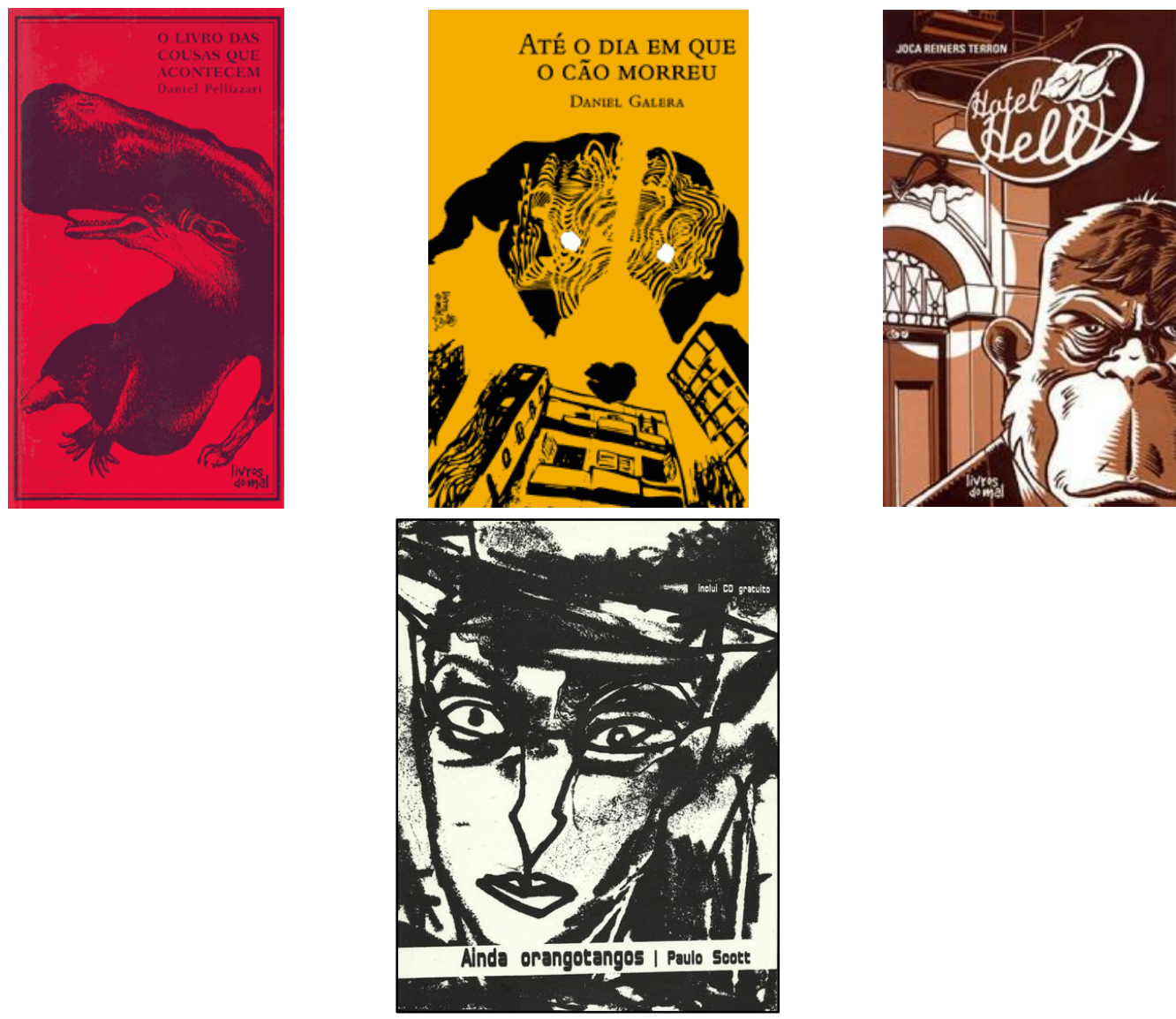

Figura 5 - Capas dos livros da Coleção Tumba do Cânone.

Fonte: Catálogo da Livros do Mal. ${ }^{19}$

\footnotetext{
${ }^{19}$ Disponível em: http://www.cabrapreta.org/ldm/
} 
O livro das cousas que acontecem, segunda antologia de contos de Pellizzari, ilustrado por seu irmão, Luiz Pellizzari, é definido pelo autor como um livro de fábulas metarrealistas. Nessa segunda obra, Pelizzari intensifica seu mergulho no estranhamento - anunciado pelo animal imaginário e impossível que ilustra a capa, e deriva pela metaficção, transformando escritores famosos em personagens de suas narrativas. Na página da editora é possível ler um trecho selecionado para divulgação do título:

Em um dia ímpar de junho, e estava frio, Douglas leu na página 10 de um jornal de bairro, reservada a uma seção de curiosidades, que o espirro é a segunda sensação física mais forte que pode ser experimentada pelos humanos. A primeira da lista, ainda segundo a seção de curiosidades da página 10 de um jornal de bairro, é o orgasmo. [...] Douglas conseguiu finalmente espirrar e ter um orgasmo ao mesmo tempo. Achou bom, mas ponderou que, para algo a que se dedicou tanto, poderia ter sido melhor, até porque no momento exato não conseguiu decidir se mantinha a concentração no espirro ou no orgasmo ou nos dois ao mesmo tempo e acabou prestando mais atenção nesta dúvida, que permanece, pois em nenhuma das quatrocentas e dezoito vezes subsequentes em que repetiu a experiência teve calma para chegar a uma decisão sobre o que deveria sentir (Pellizzari, 2002).

Até o dia em que o cão morreu, segunda publicação de Galera e sua primeira narrativa longa, mantém o tom coloquial que teve destaque em sua primeira publicação. A narrativa em primeira pessoa apresenta o cotidiano tedioso, solitário e sem expectativas de um jovem formado em Letras e desempregado, que tem dificuldade em manter seus laços afetivos. $O$ trecho selecionado para divulgação do título na página da editora o personagem narra:

Foram dias esquisitos. Na tentativa desesperada de me ocupar, retomei o hábito de ler. Lia pelo menos quatro ou cinco horas por dia, e depois ia pro computador do escritório, ver putaria na internet. Lentamente, comecei a escrever o esboço de um projeto prum mestrado em Literatura Comparada. Mas não adiantava ter pressa, ainda faltavam alguns meses pro início do prazo de inscrições na Universidade Federal. Telefonei pra velhos professores e encontrei um que estava disposto a me orientar. Nas horas mais vazias, eu caminhava sem objetivo pela Ipiranga, fumando e tentando ter alguma ideia. Nos primeiros dias, o cachorro me seguia, acompanhávamos um ao outro, num transe semelhante. Era a companhia ideal pra mim. Total ausência de palavras. Apenas alguns olhares cúmplices, e mais nada. Assim como ele, eu só queria me adaptar à civilização na medida em que isso era necessário à minha sobrevivência (Galera, 2003).

Hotel Hell, quarto livro de Joca Reiners Terron e sua segunda novela, é uma compilação de microcontos, anteriormente publicados como posts em seu blog e, posteriormente, estruturados no formato de novela para essa publicação. No trecho selecionado para divulgação do título na página da editora tem-se uma amostra:

As crianças brincam lá embaixo, no playground. No horizonte, encobrindo a cordilheira de prédios, a Primavera se aproxima, adiantada. E tudo para. Desço então os quinhentos lances da escadaria num só impulso. Quando chego ao térreo é possível ver seus primeiros raios encobrindo o edifício enorme a três quarteirões daqui. Em meio aos carros, minha roda direita esbarra num sedan. O alarme é acionado, mas sigo em frente, desviando do latão de lixo no caminho, através da garagem. A Primavera está chegando, fora de hora. [...]. Continuo correndo, resgato energias não sei de onde e aumento a marcha. Quase atinjo a grade do playground e posso ver nossa filha, sozinha, no topo aceso da roda-gigante. [...]. Entro no recinto a uma velocidade inimaginável para uma cadeira de rodas (Terron, 2003).

Ainda orangotangos, segunda publicação de Paulo Scott, é uma antologia de contos narrados em primeira pessoa que tem como temática o cotidiano de jovens da classe média portoalegrense e suas desventuras amorosas, atravessadas por drogas e referências musicais. Cada conto dialoga com uma canção de um artista gaúcho, que poderiam ser escutadas no CD que acompanhava a publicação. Trecho selecionado para divulgação do título na página da editora:

Abro tua boca, observo tua língua querendo azular, recordo tua expressão de espanto naquela noite em que nos conhecemos na estação de alpinismo, quando, num beijo afoito, descobriste que eu não tinha língua e também o fato de teres me aceitado sem medo. Mas 
isso agora é passado. Aperto firme tua língua, arranco-a sem vacilo, beijo tua boca pela última vez, tomando-te como par. Misturado no sangue, sinto o doce da tua saliva, sugo-o sem engolir (Scott, 2003).

Conforme Galera, o encerramento das atividades da LdM derivou do próprio sucesso do projeto, que foi ganhando proporções que os obrigaram (ele e Pelizzari), "a fazer uma escolha: ser editores ou ser autores/tradutores", pois, segue o escritor "É dificílimo conciliar os dois" (Galera, 2006).

Essa breve revisão das publicações da LdM visou enfatizar alguns dos fios condutores que as entrelaçam. Em relação à temática, como se observa nos trechos escolhidos para a divulgação dos títulos na página da editora, reconhecemos a recorrência de alguns repertórios: a associação à tradição dos gêneros fantástico e absurdo, bem como a episódios escatológicos, grotescos e sexualmente explícitos; e tramas que, geralmente, buscam revelar o estranhamento que está presente no cotidiano ou surpreender o leitor transformando o realismo em absurdo. Nesse sentido, o nome da editora, em sua relação anunciada pela epígrafe com a literatura de Bataille, é ressignificado pelas diversas cenas perversas, cruéis e bizarras que permeiam essas narrativas do Mal, as quais quase sempre confrontam padrões e valores morais, buscando cruzar o limite do permitido e do aceitável, procurando causar estranheza e desconcertar o leitor. É uma prosa centrada no urbano e na classe média e, apesar de alguns regionalismos, narrativamente globalizada. É fácil reconhecer como essas obras configuram ou reafirmam vertentes da literatura brasileira contemporânea que seriam, posteriormente, elencadas por Rinaldo de Fernandes:

1) a da violência ou brutalidade no espaço público e urbano; 2) a das relações privadas, na família ou no trabalho, em que aparecem indivíduos com valores degradados, com perversões e não raro em situações também de extrema violência, física ou psicológica; 3) a das narrativas fantásticas, na melhor tradição do realismo fantástico hispano-americano, às quais se podem juntar as de ficção científica e as de teor místico/macabro; 4) a dos relatos rurais, ainda em diálogo com a tradição regionalista; 5) a das obras metaficcionais ou de inspiração pósmoderna. O que une todas essas vertentes é o olhar cruel e irônico sobre as situações configuradas. O olhar cruel sobre a existência que os nossos melhores contistas herdaram de Machado de Assis (Fernandes, 2012, p. 175).

Os autores publicados pela LdM experimentam vários estilos e formatos literários, mas, corroborando o que aponta Fernandes sobre essa geração, há uma preferência pelo conto. Outra característica marcante dessas obras é a opção pela linguagem coloquial, quase como um manifesto, que parece vir justamente para disfarçar a origem extremamente literária dessas narrativas. E, nesse sentido, o descaso à norma culta da língua portuguesa, quando ocorre, é meticulosamente articulado e esteticamente pensado.

Advindos do contexto interativo da internet, os editores/autores da LdM buscaram seguir falando diretamente a seus leitores, principalmente, para não dizer exclusivamente, por meio da internet, mantendo a linguagem meticulosamente informal que caracterizou suas publicações. Além disso, o fato de serem "desbravadores" da produção de conteúdo no universo virtual, um meio que começava a mostrar suas potencialidades, transformou-os em uma espécie de porta-vozes desse novo meio e de uma geração que surgia. Utilizando o bordão regional porto-alegrense: "trimmmassa" (tri massa), que poderia ser traduzido ao português neutro como: "muito bom" ou "muito legal", a editora logrou transferir os leitores das publicações virtuais para as publicações impressas, estabelecendo, entre outras coisas, um jogo de identificação muito forte com o público regional, o que, no entanto, não prejudicou a comunicação com outras regiões do país.

O sucesso da editora e de suas publicações e, por consequência, a inserção imediata dessas obras e de seus autores no sistema literário brasileiro podem ser reconhecidos, por exemplo, na participação de seus escritores/editores com sessões de autógrafos e oficinas na Feira do Livro de Porto Alegre 20 de 2001. Apesar de celebrarem e divulgarem a participação nesse espaço

\footnotetext{
${ }^{20}$ A Feira do Livro de Porto Alegre acontece de maneira ininterrupta há 60 anos na Praça da Alfândega, Centro de Porto Alegre, tradicionalmente entre o final de outubro e o meio de novembro. Além das inúmeras bancas de livreiros, das sessões de lançamento e de autógrafo, são oferecidas várias atividades culturais que envolvem os vários centros culturais (Santander Cultural, Museu de
} 
consagrado e consagrador do sistema literário gaúcho, os autores fizeram questão de manter um discurso coloquial, irreverente e um tanto irônico em relação a sua participação, anunciando "dedicatórias constrangedoras", realizadas em um "clima de dignidade artística" sem se absterem das "piadas internas" e com "emoção guei".

No mesmo sentido, a conclamação da editora à oficina de criação literária ministrada por Pellizzari e Galera na Feira - atividade que não apenas reconhece e corrobora o status de ambos como escritores mas também já os coloca no patamar privilegiado do sistema literário de detentores do saber literário - visa desconstruir a imagem clássica da oficina como um espaço destinado à erudição literária, aproximando-a social e culturalmente do contexto e da linguagem do público jovem de suas publicações, como fica explícito nos objetivos divulgados: “Explorar a criatividade literária com exercícios supimpas que envolverão imagens de seres decapitados e musiquinhas do Mogway, entre outras diversões". E, certamente, o convite à participação no evento resultou do reconhecimento do potencial da editora, de seus produtos e de seus autores em relação ao público jovem e à nova linguagem, então emergente, da internet, instâncias que já se anunciavam indissociáveis. Outro elemento legitimador da editora e de seus produtos foi a tradução e publicação, em 2002, de seus dois primeiros livros na Itália. Estava feita e consumada a passagem do underground cultural virtual para o mainstream do sistema literário impresso.

Vale destacar ainda que, apesar das notórias aspirações à contracultura e do aparente interesse em desconstruir paradigmas do sistema literário, o perfil dos autores publicados pela LdM corrobora as estatísticas referentes ao sistema literário brasileiro contemporâneo. A pesquisa desenvolvida por Regina Dalcastagnè, referente aos romances publicados pelas principais editoras brasileiras, cujos dados foram apresentados e analisados em Literatura brasileira contemporânea: um território contestado (2012), constatou que o escritor brasileiro contemporâneo é: homem $(72,7 \%)$, branco $(93,9 \%)$, de classe-média, cursou ensino superior e reside no eixo Rio de Janeiro (47,3\%)-São Paulo (21,2\%). O único aspecto desviante no perfil dos escritores publicados pela LdM era o lugar de onde enunciavam, uma vez que, durante a atuação da editora, todos estavam fora do eixo Rio de Janeiro-São Paulo, notoriamente conhecido por congregar a produção cultural do país.

Os autores da LdM foram inseridos em coletâneas como Geração 90: os transgressores (2003), organizada pelo escritor Nelson Oliveira, que retoma a proposição de Antonio Candido dos transgressores literários como transrealistas, que "por conta dessa transa trans, conseguem ser mais realistas que o rei" (Oliveira, 2003, p. 15). Mas esse manifesto de transgressão foi atacado por Jerônimo Teixeira no texto "A horda dos transgressores: eles acham que estão quebrando tudo, mas fazem uma literatura pueril", publicado na Veja, em março de 2006, no qual, ironicamente, ele ensina como escrever um texto transgressor: escreva com desleixo; seja nojento; fale de sexo selvagem; crie personagens "malditos"; e seja narcisista (Teixeira, 2006). Sem entrar no mérito da discussão estabelecida entre os dois textos críticos, o fato de as publicações da LdM serem reconhecidas como objetos de análises literária e a fortuna crítica que vem sendo produzida a seu respeito as legitimam e empoderam, bem como a seus autores, no sistema literário nacional e internacional.

\section{O legado da LdM}

As obras publicadas pela LdM interferiram no sistema literário brasileiro, contribuindo para a reconfiguração e reformulação dos modelos canônicos da literatura contemporânea nacional, ao mesmo tempo em que foram incorporadas/canonizadas pela estrutura do sistema que questionavam. Isso ocorre, por um lado, em função do que Even-Zohar (2003b) denominou de canonicidade estática - quando um texto é aceito como um produto concluído, sendo inserido no conjunto de textos escolhidos para serem preservado (na literatura e na cultura); o que se

Arte do Rio Grande do Sul, Memorial do Rio Grande do Sul e Centro Cultural CEEE Erico Veríssimo) existentes no entorno da praça. Já passaram pela feira grandes nomes da literatura nacional e internacional. Em 2010, foi reconhecida como Patrimônio Imaterial da cidade. 
configuraria, por exemplo, com a reedição de títulos lançados pela LdM por outras e consagradas editoras. Mas também se dá pela canonicidade dinâmica (Even-Zohar, 2003b), quando o sucesso de um repertório faz com que um modelo literário se estabeleça como um princípio produtivo no sistema - notoriamente, alguns repertórios oriundos ou visibilizados pelas publicações da LdM tornaram-se recorrentes na literatura brasileira contemporânea. Podemos reconhecer a forma como fenômenos e repertórios que estavam na periferia do sistema literário no contexto independente das publicações da editora foram aos poucos abrindo espaço rumo ao centro mais prestigioso do sistema literário e à canonização.

Se o sucesso vertiginoso dos produtos da LdM não garantiu a persistência do projeto, que encerrou suas atividades em 2004, deixando algumas metas pelo caminho, como a publicação de suas "primeiras autorAs" e o desejo de aventurar-se por outras artes, entretanto, sua produção continuou reverberando no sistema cultural brasileiro, como nas adaptações teatrais de Ovelhas que voam se perdem no céu, Dentes guardados e Ou clavículas, realizadas por Mário Bortolotto, em 2003; e nas adaptações para o cinema, em 2007, de Até o dia em que o cão morreu, por Beto Brant, rebatizado como Cão sem dono, e Ainda orangotangos, realizada por Gustavo Spolidoro. E, em 2014, dez anos após o final de atividades da editora e onze anos após a realização das primeiras adaptações, quando Bortolotto repaginou suas adaptações teatrais em uma série de espetáculos intitulada Peças du Mal.

Com o encerramento das atividades da LdM, cada um dos editores/autores partiu então em carreira solo. E a analogia com o final de uma banda é proposital, uma vez que esse pequeno grupo compartilhou suas atividades com intensidade e irmandade similar a dos grupos musicais. Essa mesma associação também foi feita por Galera em relação ao trabalho no COL: "Éramos quase como uma banda, só que fazendo um mail-zine", e reforçada por Hermano Freitas: "eu era jovem e estudante e o COL era como a nossa banda" (Natusch, 2011, s.p.). E, assim como uma boa banda que deixou saudades, vira e mexe, eles coassinam algum trabalho. Em 2016, 15 anos após seu final, o Cardosonline foi tema de um debate na Feira do Livro de Porto Alegre, na mesa intitulada "1999 não tem fim", em que André Czarnobai, Clara Averbuck, Daniel Galera e Daniel Pellizzari conversaram sobre a experiência compartilhada e sobre a forma como essa experiência repercutiu em suas carreiras.

Oriundos do ambiente virtual da internet: blogueiros (antes do blog)/escritores que se tornaram escritores/blogueiros, Pellizzari e Galera possuem páginas pessoais respectivamente, Cabra Preta e Ranchocarne - nas quais, como em todos os blogs, a primeira coisa que se lê é o perfil do dono do espaço.

Em Cabra Preta, Pellizzari se apresenta:

Oi. Sou Daniel Pellizzari. Nasci em Manaus, cresci em Porto Alegre e moro em São Paulo. Escrevi uns livros, editei mais alguns, traduzi outros tantos. [...] Trabalho como editorexecutivo na Estação Liberdade e escrevo todo mês no blog do Instituto Moreira Salles. Fui colunista de games da Folha de S. Paulo e sou também cocriador de uma graphic novel que um dia talvez fique pronta, alimentador contumaz de álbuns de recortes e, muito vezenquando, escultor de drones. Era isso; tome lá um abraço e até mais ver (Cabra Preta, s.d.).

Daniel Galera também segue a etiqueta virtual e se apresenta em sua página pessoal:

Meu nome é Daniel Galera e nasci em julho de 1979 em São Paulo, mas sou de família gaúcha e me criei em Porto Alegre. Já adulto, vivi alguns anos em São Paulo e Santa Catarina, e hoje moro em Porto Alegre de novo. Publiquei contos e textos diversos na internet de 1996 a 2001, com destaque para os três anos como colunista do mailzine Cardosonline (COL), e lancei meus dois primeiros livros pelo selo independente Livros do Mal, criado em 2001 por mim, Daniel Pellizzari e Guilherme Pilla. Além de escrever prosa de ficção, traduzo autores de língua inglesa e de vez em quando publico resenhas, ensaios e reportagens (Ranchocarne, s.d.).

Dos três criadores da LdM - Pellizzari, Galera e Pilla - oriundos do encontro promovido pelo COL, que reconhecia a importância do ambiente e das ferramentas virtuais, atualmente, apenas Pilla possui e atualiza seu perfil pessoal no Facebook, espaço no qual posta informações sobre suas 
produções e suas atividades, além de interagir com seus fãs. Além disso, as obras de Pilla podem ser vistas em sua conta no Instagram (@pillaguilherme), Flickr e Pinterest. Pellizzarii ${ }^{21}$ e Galera ${ }^{22}$ seguem com carreiras de sucesso no sistema literário brasileiro, como autores e tradutores, tendo obras publicadas pela Companhia das Letras, uma das mais prestigiosas editoras do país, e também no sistema literário internacional, por meio de traduções de suas obras a outros idiomas. Entre suas múltiplas atividades, eles já incursionaram pelas narrativas gráficas e dedicam boa parte de seu tempo à tradução, muitas vezes realizada em conjunto. E, assim como os dois idealizadores e editores da LdM, todos os autores publicados pela editora, mesmo que exercendo concomitantemente outras atividades profissionais, seguiram carreiras literárias.

A curta, produtiva e controversa trajetória da LdM marcou seu espaço na historiografia recente da literatura nacional com um percurso meteórico que reconfigurou a perspectiva em relação à autopublicação e às editoras independentes, ressignificando posiç̃̃es e papéis do sistema literário nacional ao mesmo tempo que revalidou instituições e atores literários.

\section{Referências}

ARRAIS, Daniela (2008). E-zine Cardosonline completa dez anos. Informática. Folha de S. Paulo, Entretenimento, F6, 17 set. Disponível em: http://www.qualquer.org/cardoso/COL.pdf. Acesso em: 2 abr. 2020.

BALDI, Cristiano (2002). Ou clavículas. Porto Alegre: Livros do Mal.

BENVENUTTI, Marcelo (2002). Vidas cegas. Porto Alegre: Livros do Mal.

BULLAR, Paulo (2002). Humus. Porto Alegre: Livros do Mal.

CABRAPRETA (s.d.). Página pessoal de Daniel Pellizzari. Disponível em: http://www.cabrapreta.org Acesso em: 17 mar. 2020.

CARDOSONLINE: fanzine por e-mail (2001). Disponível em: http://www.qualquer.org/col/ Acesso em: 11 mar. 2018.

CARVALHO, Bernardo (2002). Autonomia de um conto. Folha de S. Paulo, Ilustrada, 5 jan. Disponível em: http://www1.folha.uol.com.br/fsp/ilustrad/fq0501200216.htm Acesso em: 5 abr. 2020.

COLONETTI, Milton (2010). Livros do Mal: um problema de história editorial. 2010. 118f. Dissertação (Mestrado em Literatura Brasileira) - Universidade Federal do Rio Grande do Sul, Porto Alegre. Disponível em: https://www.lume.ufrgs.br/bitstream/handle/10183/28060/000766121.pdf?sequence=1 Acesso em: 12 mar. 2020.

DALCASTAGNÈ, Regina (2012). Literatura brasileira contemporânea: um território contestado. Vinhedo: Horizonte.

\footnotetext{
${ }^{21}$ Lista de obras de Daniel Pellizzari: romances - Digam a Satã que o recado foi entendido (2013), Dedo negro com unha (2005); e contos - Melhor seria nunca ter existido (2012), O livro das cousas que acontecem (2002), Ovelhas que voam se perdem no céu (2001). Além disso, traduziu livros de autores como David Mitchell, William S. Burroughs e David Foster Wallace.

${ }^{22}$ Lista de obras de Daniel Galera: romances - Meia-noite e vinte (2016), Barba ensopada de sangue (2012), Cordilheira (2008), Mãos de cavalo (2006), Até o dia em que o cão morreu (2003); contos - Dentes guardados (2001); HQ - Cachalote (2010, em coautoria com Rafael Coutinho). Prêmios recebidos: Prêmio Machado de Assis de Romance da Fundação Biblioteca Nacional (Rio de Janeiro, 2008), por Cordilheira; Prêmio Jabuti de Literatura, terceiro lugar na categoria Romance (São Paulo, 2009), por Cordilheira; $3^{\circ}$ lugar na categoria Romance por Barba ensopada de sangue (São Paulo, 2013); Prêmio HQ Mix Novo Talento, Roteirista (São Paulo, 2010), por Cachalote; Prêmio São Paulo de Literatura 2013 - Melhor Livro do Ano, por Barba ensopada de sangue. Em 2014, organizou a antologia de contos policiais, intitulada Latinoamérica criminal, publicada pela Literatura Random House, na qual convidou jovens autores de diversos países do continente a escreverem um conto de cunho "criminal" ambientado em seu país natal.
} 
DEVES, Maristela Scheuer (2016). "Meia-Noite e Vinte”, de Daniel Galera, traça retrato de uma geração. Pioneiro, Cultura e lazer, 10 dez. On-line. Disponível em: https://bit.ly/3oYvVAu Acesso em: 27 mar. 2020.

EVEN-ZOHAR, Itamar (2003a). O sistema literário. Revista Translatio, Porto Alegre, n. 3, p. 1-24. Disponível em: http://seer.ufrgs.br/index.php/translatio/article/view/42900 Acesso em: 23 mar. 2020.

EVEN-ZOHAR, Itamar (2003b). Teoria dos polissistemas. Revista Translatio, Porto Alegre, n. 3, p. 1-21. Disponível em: https://seer.ufrgs.br/translatio/article/view/42899 Acesso em: 23 mar. 2020.

FERNANDES, Rinaldo de (2012). O conto brasileiro do século XXI. As narrativas curtas da nova literatura nacional divididas em cinco grandes vertentes. Revista Graphos, v. 14, n. 1, p. 173-188. Disponível em: https://periodicos.ufpb.br/ojs2/index.php/graphos/article/view/13407/8087 Acesso em: 24 mar. 2020.

GALERA, Daniel (2001). Dentes guardados. Porto Alegre: Livros do Mal.

GALERA, Daniel (2002). Um mouse na mão e muitas idéias na cabeça. [Entrevista a] Alexandre Inagaki. Prólogo. Disponível em: http://cabrapreta.org/ldm/clip_prologo.html Acesso em: 23 mar. 2020.

GALERA, Daniel (2003). Até o dia em que o cão morreu. Porto Alegre: Livros do Mal.

GALERA, Daniel (2006). [Entrevista a] Julio Daes Borges. Digestivo Cultural, 12 jun. Disponível em: http://www.digestivocultural.com/entrevistas/entrevista.asp?codigo=2\&titulo=Daniel_Galera Acesso em: 19 dez. 2019.

GALERA, Daniel; PELLIZZARI, Daniel; PILLA, Guilherme (2003). O projeto. CabraPreta - Página pessoal de Daniel Pellizzari. Disponível em: http://cabrapreta.org/ldm/projeto.html Acesso em: 9 abr. 2020.

GALERA, Daniel; PELLIZZARI, Daniel; PILLA, Guilherme (2002). Sob a bandeira d'O Pinto. [Entrevista a] Rodolfo Filho. A Tarde, out. Disponível em: http://cabrapreta.org/ldm/clip_atarde.html Acesso em: 17 mar. 2020.

GÓIS, Marco Lúcio de Souza (2015). As faces de Bakhtin: uma análise discursiva de capas de livros. Linguagem em (Dis)curso - LemD, Tubarão, v. 15, n. 3, p. 431-448, set./dez. Disponível em: http:/ /www.scielo.br/pdf/ld/v15n3/1518-7632-ld-15-03-00431.pdf Acesso em: 15 mar. 2020.

GUILHERME Pilla. Perfil no Flickr. Disponível em: https://www.flickr.com/photos/guipilla/ Acesso em: 9 mar. 2020.

NATUSCH, Igor (2011). Literatura na internet: a egotrip do Cardosonline, um século depois. Sul 21, 10 set. Disponível em: https://www.sul21.com.br/noticias/2011/09/a-grande-egotrip-do-cardosonline-umseculo-depois/ Acesso em: 15 mar. 2020.

OLIVEIRA, Nelson (2003). Geração 90: os transgressores. São Paulo: Boitempo Editorial.

PELLIZZARI, Daniel (1997). Quatro gargantas cortadas. Folhetim. On-line. Disponível em: http://cabrapreta.org/4gc/ Acesso em: 23 mar. 2020.

PELLIZZARI, Daniel (2001). Ovelhas que voam se perdem no céu. Porto Alegre: Livros do Mal.

PELLIZZARI, Daniel (2002). O livro das cousas que acontecem. Porto Alegre: Livros do Mal.

RANCHOCARNE. Página pessoal de Daniel Galera. Disponível em: http://www.ranchocarne.org/ Acesso em: 17 mar. 2020.

SCOTT, Paulo (2003). Ainda orangotangos. Porto Alegre: Livros do Mal.

TEIXEIRA, Jerônimo (2006). A horda dos transgressores. Veja, São Paulo, $1^{\circ}$ mar.

TERRON, Joca Reiners (2003). Hotel Hell. Porto Alegre: Livros do Mal.

TRASEL, Marcelo (2001). Prosa gaúcha sem sotaque. Carta Capital, n. 161, p. 6317, out. Disponível em: http:/ / cabrapreta.org/ldm/clip_carta.html Acesso em: 7 abr. 2020. 